\title{
Prophylactic versus therapeutic left ventricular unloading during extracorporeal membrane oxygenation, better safe than sorry?
}

\author{
Pieter S. van der Wal ${ }^{1}$, Myrthe P. J. van Steenwijk ${ }^{1}$, Leon J. Montenij ${ }^{2}$, Dirk W. Donker ${ }^{1}$, \\ Christiaan L. Meuwese ${ }^{1}$ \\ ${ }^{1}$ Department of Intensive Care, University Medical Center Utrecht, Utrecht, The Netherlands; ${ }^{2}$ Department of Intensive Care, Catharina Hospital, \\ Eindhoven, The Netherlands \\ Correspondence to: Christiaan L. Meuwese. Department of Intensive Care, University Medical Center, Utrecht, The Netherlands. \\ Email: c.l.meuwese@umcutrecht.nl. \\ Comment on: Na SJ, Yang JH, Yang JH, et al. Left heart decompression at venoarterial extracorporeal membrane oxygenation initiation in cardiogenic \\ shock: Prophylactic versus therapeutic strategy. J Thorac Dis 2019;11:3746-56.
}

Submitted Aug 29, 2020. Accepted for publication Sep 18, 2020.

doi: $10.21037 /$ jtd-20-2771

View this article at: http://dx.doi.org/10.21037/jtd-20-2771

In a previous edition of this Journal, an interesting study was presented addressing the impact of prophylacticversus therapeutic-left ventricular (LV) unloading on mortality in patients being supported with veno-arterial extracorporeal membrane oxygenation (VA-ECMO) for cardiogenic shock (1). Main findings suggested that survival might be better in those who received LV unloading in a prophylactic fashion as compared with application in a therapeutic manner. These results led the authors to conclude that prophylactic LV unloading may improve patient prognosis as compared with delaying its application until disease progression would have occurred. From both a clinical as well as pathophysiological view, the authors have touched upon a very interesting topic and provide novel evidence on this matter and prospective, multi-center investigations are needed to confirm the results.

Despite its great potential for rapid stabilization of patients with cardiogenic shock, VA-ECMO is associated with numerous complications, some of which can occur as a consequence of high LV afterload (2,3). High LV afterload, being imposed by the interaction of the VA-ECMO circuit and the native heart, may lead to high $L V$ preload, LV distention, stasis of blood and pulmonary edema which could in turn prevent cardiac recovery, successful weaning from VA-ECMO and ultimately cause death. It seems vital to intervene timely in this cascade in order to prevent this dreadful outcome to occur. In the current study (1), $\mathrm{LV}$ preload was reduced through placement of a surgical or percutaneous vent in the left atrium or ventricle. Left venting is an example of an unloading technique which directly reduces $L V$ preload. In general, $L V$ preload can also be directly reduced by creation of an atrial septostomy, a technique most commonly utilized in pediatric populations. $\mathrm{LV}$ unloading techniques can also exert indirect effects on preload by lowering $\mathrm{LV}$ afterload as provided by an intraaortic balloon pump (IABP) and micro-axial blood pump (Impella $^{\circledR}$ ) (3). These devices carry the advantage that they can be left in place after VA-ECMO decannulation when a step-down is indicated (4).

Deciding on which LV unloading technique is most appropriate in a specific situation remains a clinical challenge. Arguments fuelling this discussion may relate to anatomical constraints of a patient, device specific side effects or complications as well as to the required degree of LV unloading. For example IABP, as an adjunct to VAECMO, is associated with only marginal decreases in LV filling pressures (5) but on the other hand has a relatively favourable risk profile (6). In addition, many centres have a large body of experience with this device and costs are relatively low. Patients in need of more potent unloading may benefit from a micro-axial blood pump (Impella), yet, the downsides of this device might be an increased incidence of hemolysis and significant costs (7). Small or fragile peripheral arteries may lead to a preference for LV venting or transseptal LA drainage, especially when interventional or surgical expertise is available. A transseptal 


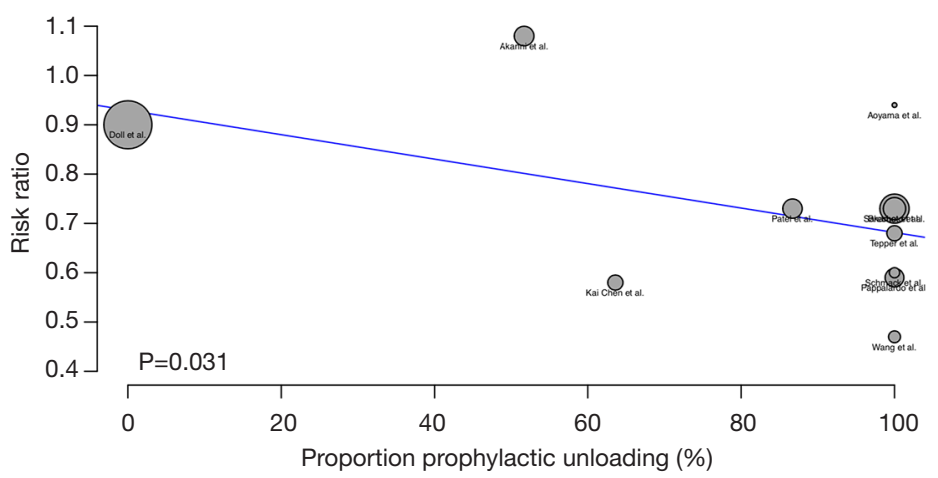

Figure 1 The association between the proportion of prophylactic unloading in each cohort and its corresponding risk ratio. A Bubble plot illustrating the association between the proportion of prophylactic unloading in each cohort and its corresponding risk ratio. A lower risk ratio implies increased survival benefit of unloading versus no unloading.

puncture can however impose a certain risk for cardiac tamponade. To our knowledge, the exact increase in device specific complication risk on top of that of VA-ECMO has never been quantified. Studies into the different unloading devices without VA-ECMO show great variations in risk estimations for vascular damage, bleeding, cerebrovascular accidents and other device specific complications (8).

$\mathrm{LV}$ unloading during VA-ECMO in general seems associated with lower mortality as was recently suggested by a meta-analysis of observational studies (9). This association persisted when risk ratios were pooled which were specifically adjusted for confounding effects in each study (10). For these analyses however, the timing of LV unloading initiation was not taken into account. Theoretically, the observed benefit could be driven by a subset of patients who received $\mathrm{LV}$ unloading after a certain time point. This time point would reflect the threshold where the advantage of unloading for the prevention of afterload related complications outweighs the additional risks imposed by device placement. Interestingly, some of the included cohorts in the meta-analysis by Russo et al. (9) provided details on timing of $\mathrm{LV}$ unloading. For the purpose of this editorial, we examined the association between the proportion of patients who received $L V$ unloading as prophylaxis in each study and its corresponding risk ratio. Figure 1 shows results from a Bubble plot illustrating the risk ratio as a function of the proportion of patients in whom LV unloading was applied in a prophylactic fashion. An inverse and significant association is observed between both variables implying a higher degree of mortality reduction due to prophylactic unloading than therapeutic unloading (1).
Findings from observational studies comparing treatment strategies should be interpreted with caution as they are typically hindered by several sources of systematic error. Firstly, as allocation of treatment strategies is not randomized, confounding by indication can compromise findings (11). In the current study, effect estimates were not adjusted for potentially confounding factors. When reviewing the distribution of baseline characteristics in both unloading groups, substantial differences seem to exist in causes of cardiogenic shock and percentage of patients requiring continuous veno-venous hemofiltration. Also, a considerably higher percentage of patients received surgical venting in the treatment unloading group which might reflect differences in complications and etiology of heart failure. These differences are likely to have impacted on mortality whereby causing confounding effects in the association of interest.

Systematic error could also have arisen due to bias as a consequence of selecting patients for the therapeutic unloading group at a different time point than those for the prophylactic unloading group. Patients who would be selected after having undergone therapeutic LV unloading would be required to have survived up till the time point of receiving this intervention. By virtue of this design, these individuals start with a considerable advantage in event free follow-up as compared to their counterparts in the prophylactic group. The overestimation of event-free follow-up in the therapeutic unloading group could lead to so called "immortal time bias" (12). In the current report, this immortal time appeared to be a median 39 hours (interquartile range, 13-101 hours) in the therapeutic unloading group. Oppositely to what would have been 
expected from this bias however, the therapeutic unloading group had poorer survival as compared to the prophylactic group. This difference is not likely explained by immortal time bias. Besides an effect of differential sampling in both groups on event-free survival, selection of "survivors" who develop an indication for LV unloading could also have resulted in a group with much higher risk for mortality. This could be the case as their disease progresses and weaning was not yet successfully accomplished up till that time point. Indeed, a strong association was observed between prolonged ECMO support and an increased mortality (13).

When considering solutions for these methodological limitations in observational studies investigating treatment effects, it is of great help to conduct an imaginary experiment by designing a randomized clinical trial on the topic (14). In an imaginary randomized clinical trial investigating the impact of prophylactic versus therapeutic unloading on outcome, patients would be randomized at the moment of VA-ECMO implantation. Individuals who would be allocated to the prophylactic group would receive an unloading device at the same time as they would receive VA-ECMO. Patients who would be randomized to the therapeutic unloading group would be followed-up until developing pulmonary edema (or another threshold for decision making is surpassed) after which also an unloading device would be placed. In an intention to treat analyses, calculations in the therapeutic group would also contain those patients who died before receiving an unloading device. If these individuals would be left out (such is the case in a per-protocol analysis), confounding could be introduced as randomization is ignored. This imaginary experiment teaches us that also in observational analyses, comparisons between treatment strategies should include patients who died before receiving an unloading device. This could be done by matching patients in both groups on followup duration after ECMO implantation or adding a time dependent covariate (15). Finally, as observational studies lack randomization, the potential of confounding should be mitigated by means of statistical techniques. These may be stratification, matching, correction for covariates, or more sophisticated techniques such as propensity scores or inverse probability weighting.

All in all, the current study by $\mathrm{Na}$ et al. provides interesting and novel data on the association between timing of LV unloading and mortality. Results suggest that prophylactic versus therapeutic unloading is potentially associated with reduced mortality. The studies' conclusions find support in results from our meta-regression analysis of current literature. As these observational comparisons are however typically hindered by distorting effects due to both bias and confounding, further studies are urgently needed to elucidate the real impact of prophylactic versus therapeutic unloading during VA-ECMO on mortality. Preferably, a randomized controlled trial should be undertaken.

\section{Acknowledgments}

Funding: None.

\section{Footnote}

Provenance and Peer Review: This article was commissioned by the editorial office, Fournal of Thoracic Disease. The article did not undergo external peer review.

Conflicts of Interest: All authors have completed the ICMJE uniform disclosure form (available at http://dx.doi. org/10.21037/jtd-20-2771). Dr. DWD reports personal fees from Getinge Maquet, personal fees from Xenios Novalung Fresenius, outside the submitted work. The other authors have no conflicts of interest to declare.

Ethical Statement: The authors are accountable for all aspects of the work in ensuring that questions related to the accuracy or integrity of any part of the work are appropriately investigated and resolved.

Open Access Statement: This is an Open Access article distributed in accordance with the Creative Commons Attribution-NonCommercial-NoDerivs 4.0 International License (CC BY-NC-ND 4.0), which permits the noncommercial replication and distribution of the article with the strict proviso that no changes or edits are made and the original work is properly cited (including links to both the formal publication through the relevant DOI and the license). See: https://creativecommons.org/licenses/by-nc-nd/4.0/.

\section{References}

1. Na SJ, Yang JH, Yang JH, et al. Left heart decompression at venoarterial extracorporeal membrane oxygenation initiation in cardiogenic shock: Prophylactic versus therapeutic strategy. J Thorac Dis 2019;11:3746-56.

2. Meuwese CL, Ramjankhan FZ, Braithwaite SA, et al. Extracorporeal life support in cardiogenic shock: 
Indications and management in current practice. Neth Heart J 2018;26:58-66.

3. Keebler ME, Haddad EV, Choi CW, et al. Venoarterial Extracorporeal Membrane Oxygenation in Cardiogenic Shock. JACC Heart Fail 2018;6:503-16.

4. Fried JA, Masoumi A, Takeda K, et al. How I approach weaning from venoarterial ECMO. Crit Care 2020;24:307.

5. Meuwese CL, de Haan M, Zwetsloot PP, et al. The hemodynamic effect of different left ventricular unloading techniques during veno-arterial extracorporeal life support: a systematic review and meta-analysis. Perfusion 2020;35:664-71.

6. Donker DW, Brodie D, Henriques JPS, et al. Left ventricular unloading during veno-arterial ECMO: a review of percutaneous and surgical unloading interventions. Perfusion 2019;34:98-105.

7. Pappalardo F, Schulte C, Pieri M, et al. Concomitant implantation of Impella ${ }^{\circledR}$ on top of veno-arterial extracorporeal membrane oxygenation may improve survival of patients with cardiogenic shock. Eur J Heart Fail 2017;19:404-12.

8. Subramaniam AV, Barsness GW, Vallabhajosyula S, et al. Complications of Temporary Percutaneous Mechanical Circulatory Support for Cardiogenic Shock: An Appraisal of Contemporary Literature. Cardiol Ther 2019;8:211-28.
9. Russo JJ, Aleksova N, Pitcher I, et al. Left Ventricular Unloading During Extracorporeal Membrane Oxygenation in Patients With Cardiogenic Shock. J Am Coll Cardiol 2019;73:654-62.

10. Meuwese CL, Koudstaal S, Braithwaite S, et al. Left Ventricular Unloading During Extracorporeal Membrane Oxygenation: Insights From Meta-Analyzed Observational Data Corrected for Confounders. J Am Coll Cardiol 2019;73:3034-5.

11. Jager KJ, Zoccali C, Macleod A, et al. Confounding: what it is and how to deal with it. Kidney Int 2008;73:256-60.

12. Hanley JA, Foster BJ. Avoiding blunders involving 'immortal time'. Int J Epidemiol 2014;43:949-61.

13. Distelmaier K, Wiedemann D, Binder C, et al. Duration of extracorporeal membrane oxygenation support and survival in cardiovascular surgery patients. J Thorac Cardiovasc Surg 2018;155:2471-6.

14. Hernán MA, Sauer BC, Hernández-Díaz S, et al. Specifying a target trial prevents immortal time bias and other self-inflicted injuries in observational analyses. J Clin Epidemiol 2016;79:70-5.

15. Shariff SZ, Cuerden MS, Jain AK, et al. The secret of immortal time bias in epidemiologic studies. J Am Soc Nephrol 2008;19:841-3.
Cite this article as: van der Wal PS, van Steenwijk MPJ, Montenij LJ, Donker DW, Meuwese CL. Prophylactic versus therapeutic left ventricular unloading during extracorporeal membrane oxygenation, better safe than sorry? J Thorac Dis 2020;12(11):6412-6415. doi: 10.21037/jtd-20-2771 